\title{
Surface modification of olive stone wastes for enhanced sorption properties of cadmium and lead ions
}

\author{
Mahmoud Belalia $^{1 *}$, Meriem Bendjelloul ${ }^{2}$, Abdallah Aziz ${ }^{3}$, El hadj Elandaloussi ${ }^{2}$ \\ 1 SEA2M Laboratoiry, University of Abdelhamid Ibn Badis, 27000 Mostaganem, Algéria \\ ${ }^{2}$ ESNVTA Laboratoiry, Ahmed Zabana University Center, Bourmadia, 48000 Relizane, Algéria, \\ ${ }^{3}$ Laboratory for the Valorization of Materials, University of Abdelhamid Ibn Badis, 27000 Mostaganem, \\ Algéria
}

\begin{abstract}
This paper reports the synthesis and characterization of an efficient anionic olive stone wastes-based material as new ion-exchanger adsorbent. The olive stone wastes were subjected to an alkaline pretreatment in order to enhance their reactivity towards maleic anhydride. The maleated material MOS was characterized by FTIR, ${ }^{13} \mathrm{C}$ NMR, TGA and DSC. The resulting sodiated material NaMOS was subjected to batch experiments in order to evaluate its cadmium and lead removal efficiency. Adsorption experimental data showed a uniform and rapid process. Both Langmuir and Freundlich isotherm models were found to fit adequately the equilibrium isotherm data. The sorption capacities reached $240.96 \mathrm{mgCd} \mathrm{g} \mathrm{g}^{-1}$ and $127.38 \mathrm{mgPb} \mathrm{g}^{-1}$. Thermodynamic parameters showed that the process was exothermic and the adsorption occurred spontaneously. Desorption experiments show a quantitative recovery of the metal ions from NaMOS material.
\end{abstract}

Keywords: alkaline treatment; functionalization; metal removal; olive stone; regeneration; sorption. 